\title{
Uroflowmetry in Non-Monosymptomatic Nocturnal Enuresis in Children of Coastal Region of Croatia
}

\author{
Sandra Prgomet ${ }^{1}$, Marjan Saraga ${ }^{1}$, Sandra Benzon ${ }^{2, *}$, Daniel Turudić ${ }^{3}$, Dragan Ledina ${ }^{4}$, Danko Milošević ${ }^{3}$
}

\begin{abstract}
Purpose: The aim of the study was to describe clinical characteristics and bladder assessment in children with Non-Monosymptomatic Nocturnal Enuresis (NMNE) in coastal region of Croatia.

Materials and methods: Records on 85 patients with NMNE were retrospectively reviewed. Bladder assessments were performed in all children. In this research we: (i) compare clinical characteristics and features of bladder assessment: uroflowmetry, post void residuals (PVR) and bladder wall thickness between boys and girls with NMNE and we compare (ii) clinical characteristics and bladder assessment between children with primary and secondary NMNE.

Results: There were 46 girls and 39 boys. The total of 59 children had primary NMNE and 26 children had secondary NMNE. Uroflow pattern was abnormal in $42 \%$ of all children with NMNE. Abnormal uroflow pattern in children with NMNE was more often in girls than in boys $(P<0.05)$ and in children with secondary than in children with primary NMNE $(P<0.05)$. Ultrasound evidence of bladder wall thickness was more frequent in boys than in girls. Girls were more likely to have dysfunctional voiding and larger residual urinary volume than boys. Conclusions: Abnormal uroflow pattern in children with NMNE was more often in girls than boys and in children with secondary than in children with primary NMNE.
\end{abstract}

\section{KEYWORDS}

nocturnal enuresis; non-monosymptomatic nocturnal enuresis; uroflowmetry

AUTHOR AFFILIATIONS

${ }^{1}$ Department of Pediatrics, Split University Hospital, University of Split, Split, Croatia

2 Department of Obstetrics and Gynecology, Split University Hospital, University of Split, Split, Croatia

${ }^{3}$ Department of Pediatrics, Zagreb University Hospital, University of Zagreb, Zagreb, Croatia

${ }^{4}$ Department of Infectology, Split University Hospital, University of Split, Split, Croatia

* Corresponding author: Department of Gynecology and Obstetrics, Split University Hospital, Spinčićeva 1, 21000 Split; e-mail: sbenzon68@gmail.com

Received: 7 November 2019

Accepted: 19 June 2020

Published online: 1 October 2020

Acta Medica (Hradec Králové) 2020; 63(3): 113-118

https://doi.org/10.14712/18059694.2020.28

(c) 2020 The Authors. This is an open-access article distributed under the terms of the Creative Commons Attribution License (http://creativecommons.org/licenses/by/4.0), which permits unrestricted use, distribution, and reproduction in any medium, provided the original author and source are credited. 


\section{INTRODUCTION}

The International Children's Continence Society (ICCS) defines enuresis (or nocturnal enuresis, NE) as wetting in discrete portions while asleep in a child older than five (1). Primary nocturnal enuresis (PNE) is defined as nocturnal wetting in a child who has never been dry on consecutive nights for longer than 6 months. Secondary enuresis is the re-emergence of enuresis after continence has been established for at least 6 months $(1,2)$. It has been documented that $15-30 \%$ of enuretic children can experience daytime incontinence (3-6). Enuresis which occur without lower urinary tract symptoms or a history of bladder dysfunction is monosymptomatic. Enuresis with lower urinary tract symptoms such as change in voiding frequency, daytime wetting, dribbling, and holding manoeuvres is non-monosymptomatic (or polysymptomatic). Among those children with frequent NE ( 2 or more wet nights per week), $68.5 \%$ were classified as monosymptomatic and $31.5 \%$ as non-monosymptomatic (7). Nocturnal polyuria along with abnormal circadian release of antidiuretic hormone $(\mathrm{ADH})$ or arginine vasopressin (AVP) is an important contributor to NE (8). The other etiological factors are an arousal disturbance during sleep and lack of inhibition of the micturition reflex. These developmental disturbances are genetically based and can be modulated by environmental factors (9). The etiological factors of lower urinary tract symptoms and disorders are heterogeneous, based on the symptoms present (urge, voiding postponement, dysfunctional voiding etc.). Diagnosis consists of detailed medical history, clinical examination, frequency-volume charts, and appropriate investigations. In general, urodynamic studies are not required $(10,11)$.

Imaging and urodynamic studies are reserved for children with significant daytime symptoms, history or diagnosis of urinary tract infections, features suggesting structural renal abnormalities, or refractory cases (12-14). In the evaluation of non-monosymptomatic nocturnal enuresis (NMNE) the approach is still controversial with little evidence-based medicine supporting diagnostic evaluation. In children with NMNE, two diagnosis need to be considered according to the ICCS: one for lower urinary tract disorder and another for nocturnal enuresis. Proposed algorithm of strategy in managing children with daytime incontinence include bladder ultrasound, post void residuals (PVR) together with uroflowmetry (15).

\section{MATERIALS AND METHODS}

We assessed total of 85 children with NMNE (median 7.6 years, 5-18 years) who referred to the Pediatric Nephrology Clinic of the Split University Hospital from January 2014 to December 2017. The outpatient clinic for voiding disorders is the only one in the coastal region of Croatia. Informed consent has been obtained. Study have been performed according to the Declaration of Helsin$\mathrm{ki}$, and the procedures have been approved by the local ethics committee. We compare clinical characteristics and features of bladder assessment: uroflowmetry, PVR and bladder wall thickness between boys and girls with
NMNE and we compare clinical characteristics and bladder assessment between children with primary and children with secondary NMNE. We analysed medical records data retrospectively. Baseline parameters were obtained from a questionnaire for toilet training age, the history of urinary tract infection, presence of frequency, urgency, daytime incontinence and constipation; frequency volume chart for two consecutive days and first morning urine osmolality. After taking detailed individual history, a detailed physical examination and urine analysis was carried out and recorded by pediatrician. International Children's Continence Society criteria were used to define enuresis, its subtypes and lower urinary tract terminology (1). Children with neurologic deficit (myelodysplasia, spinal cord disorders and mentally retarded children) and urogenital malformations were excluded from the study. The age at which a child began to void on her or his own has been expressed in months. We have defined urinary tract infection as a history of symptomatic significant bacteriuria, with or without fever in the period prior to arriving at Pediatric Nephrology Clinic. The largest voiding volume of urine from a frequency- volume chart for two days is considered as maximum bladder capacity (MBC). We used Koff's formula to measure expected bladder capacity (EBC) according to the age: Volume $(\mathrm{ml})=($ age in years +1$) \times 30$. Bladder capacity $(B C)$ was expressed as a percentage according to the formula: $B C(\%)=M B C / E B C \times 100$. Nocturnal polyuria was calculated from frequency volume chart and defined as nocturnal production of the urine $>130 \%$ of expected bladder capacity according to the age. The Roma IV criteria was used for diagnose constipation (16). We performed a retrospective chart review of all bladder assessments: uroflowmetry, post void residuals and bladder wall thickness. Uroflowmetry and pelvic floor electromyography (EMG) were performed in all children. For the uroflowmetry test, children were asked to wait until they felt a strong desire to void. The uroflowmetry test was performed for two consecutive times and only those curves generated after adequate voided volume ( $>50 \%$ of the expected bladder capacity) were analysed. Pelvic floor EMG was done by spacing skin electrodes. We used ICCS suggested categories for normal and abnormal urine flow patterns: the normal urine flow curve is bell shaped, the abnormal urine flow patterns are tower, plateau, staccato and interrupted. Bladder ultrasound (US) was performed immediately (within 5 minutes) after voiding with $5 \mathrm{MHz}$ suprapubic ultrasound. Post void residual was estimated by the equation of height $\times$ width $\times$ depth (of the bladder) $\times 0.52 \mathrm{ml}$ (17). Bladder wall thickness $>4 \mathrm{~mm}$ in an empty bladder was considered as increased. Dysfunctional voiding was defined as contraction of the external sphincter during voiding with staccato pattern with or without an interrupted flow with post voiding residual urine above $10 \mathrm{ml}$. We compared all the clinical characteristics and features of bladder assessment between boys and girls. We also compared all the clinical characteristics and features of bladder assessment between children with primary and secondary NE and lower urinary tract symptoms.

Statistical analysis was performed using SPSS version 23 , using basic descriptive statistics, the corresponding 
parametric (t-test) and nonparametric (Chi-square) test. The level for statistical significance was set at $\mathrm{p}<0.05$.

\section{RESULTS}

Among a total of 85 children, 46 (54\%) were girls and 39 (46\%) boys (Table 1). The median age of children with NMNE was 7.6 years (Min-Max: 5-18 years). The total of 59 children (69\%) had primary NMNE and 26 (31\%) children had secondary NMNE. Patients with NMNE started to void on their own at median of 30 months (Min-Max: 14-54 months). Nocturnal urine production was increased in 27 children who had nocturnal polyuria (37\%). The mean first morning urine osmolality was $827.5 \mathrm{mOsm} / \mathrm{kgH}_{2} \mathrm{O}$ $\left( \pm 257.7 \mathrm{mOsm} / \mathrm{kgH}_{2} \mathrm{O}\right)$. Children with nocturnal polyuria had lower first morning urine osmolality $(721: 905 \mathrm{mOsm} / \mathrm{kg}$, $\mathrm{p}=0.0089)$. The lower urinary tract symptoms were: daytime incontinence in $71(83 \%)$ cases, urgency in $66(80 \%)$ cases and frequency in $40(51 \%)$ cases.

Tab. 1 Descriptive statistics of the total sample $(N=85)$.

\begin{tabular}{|l|l|}
\hline Characteristics of patients & Number of patients (\%) \\
\hline Male & $39(45.88)$ \\
\hline Female & $46(54.12)$ \\
\hline Enuresis & $59(69.41)$ \\
\hline Primary & $26(30.59)$ \\
\hline Secondary & $7.6118 \pm 2.75635$ \\
\hline Age (years) & $30.4138 \pm 6.87746$ \\
\hline $\begin{array}{l}\text { The age of sphincter control } \\
\text { (months) }\end{array}$ & $23(28.40)$ \\
\hline UTI & $29(36.25)$ \\
\hline Constipation & $71(83.53)$ \\
\hline Daytime incontinence & $66(80.49)$ \\
\hline Urgency & $40(50.63)$ \\
\hline Frequency & $27(36.99)$ \\
\hline Nocturnal polyuria & $827.5400 \pm 257.76830$ \\
\hline $\begin{array}{l}\text { First morning urine osmolality } \\
\text { (mOsmol/kg) }\end{array}$ & $70.8922 \pm 29.07430$ \\
\hline Bladder capacity \% & $35(41.67)$ \\
\hline Abnormal urine flow patterns & $14.2262 \pm 13.39156$ \\
\hline Post void residual urine (ml) & $20(23.52)$ \\
\hline Dysfunctional voiding & $15(18.29)$ \\
\hline Thickened bladder wall & \\
\hline &
\end{tabular}

Legend: Values are presented as number (\%) or arithmetic mean \pm standard deviation; ${ }^{1} \mathrm{UTI}$ - positive history of urinary tract infection.

$23(28 \%)$ children had urinary tract infection. The constipation was recorded in $29(36 \%)$ children. According to frequency volume charts the average percentage of bladder capacity was $71 \%( \pm 29)$. Uroflow pattern was abnormal in $35(42 \%)$ cases. Average residual urine volume was $14.2 \mathrm{ml}( \pm 13.3 \mathrm{ml})$. Bladder wall thickness in an empty bladder was abnormal in 15 (18\%) cases. Dysfunctional voiding was recorded in 20 (24\%) of all children.

There is no statistically significant difference in the frequency of primary or secondary NMNE between boys and girls (Table 2). There was no difference according to the clinical features including the age, age of toilet training, nocturnal polyuria, bladder capacity, frequency and daytime incontinence between the boys and girls. Girls had statistically more often urinary tract infections, constipation and larger residual urine volume than boys. Abnormal uroflow and dysfunctional voiding were statistically more often in girls than boys. Urgency and ultrasound evidence of bladder wall thickness were statistically significantly more frequent in boys than girls. Abnormal uroflow pattern was statistically more often in children with secondary NMNE than in children with primary NMNE (Table 3). Uroflowmetry and pelvic floor electromyography (EMG) revealed abnormal features in $34.5 \%$ children with primary NMNE (group 1) and in $57.7 \%$ children with secondary NMNE (group 2). The following abnormal patterns in flow shapes were noted in group 1 patients: tower in 7 patients, staccato in 7 patients, interrupted in 5 patients, plateau in 1 patient. The group 2 had the following abnormal patterns: tower in 2 patients, staccato in 10 patients, interrupted in 1 patient, plateau in 2 patients. There was no statistically significant difference in other clinical characteristics between children with primary and secondary NMNE. Dysfunctional voiding was statistically more often in children with secondary NMNE than and in children with primary NMNE.

\section{DISCUSSION}

In our study, NMNE was slightly more common in females (57\%) than in males (43\%). According to the literature, the bedwetting is more common in boys whereas daytime incontinence is more common in girls (18). The one of the main etiological factors for NE is nocturnal polyuria. In our study nocturnal polyuria was equally represented in boys and girls and in both primary and secondary NMNE. Children with nocturnal polyuria, had lower first morning urine osmolality. Because of difficulty to measure the amount of urine output at night, we suggest first urine osmolality. The most important lower urinary tract symptom registered in our patients (83\%) was daytime incontinence. In the evaluation of NE by an evidence-based strategy, careful assessment of NE-related symptoms by questionnaire, physical examination, urine analysis, and frequency volume chart are only essential in the initial evaluation (13). Furthermore, the recently published $\mathrm{Na}-$ tional Institute for Health and Clinical Excellence (NICE) guidelines do not recommend even urine analysis unless there is a suspicion of recent onset, daytime symptoms, urinary tract infection, or diabetes mellitus (19). In the evaluation of NMNE, specialist referral is almost mandatory, and the approach is still controversial with little evidence-based medicine to guide treatment (11). In children with NMNE, two diagnosis need to be considered according to the ICCS: one for lower urinary tract syndrome and another for nocturnal enuresis. Proposed algorithm of 
Tab. 2 Descriptive statistics and significance of differences between boys $(N=39)$ and girls $(N=46)$.

\begin{tabular}{|c|c|c|c|}
\hline Variable & Boys (\%) & Girls (\%) & $\mathbf{P}$ \\
\hline \multicolumn{4}{|l|}{ Enuresis } \\
\hline primary & $28(71.8)$ & $31(67.4)$ & \multirow[t]{2}{*}{$.661^{\mathrm{a}}$} \\
\hline secondary & $11(28.2)$ & $15(32.6)$ & \\
\hline Age (years) & $7.03 \pm 1.885$ & $8.11 \pm 3.261$ & $.060^{\mathrm{b}}$ \\
\hline The age of sphincter control (months) & $30.04 \pm 6.523$ & $30.77 \pm 7.286$ & $.690^{b}$ \\
\hline UTI & $2(5.6)$ & $21(46.7)$ & $.000^{\mathrm{a}}$ \\
\hline Constipation & $7(19.4)$ & $22(50.0)$ & $.005^{\mathrm{a}}$ \\
\hline Daytime incontinence & $33(84.6)$ & $38(82.6)$ & $.804^{\mathrm{a}}$ \\
\hline Urgency & $34(89.5)$ & $32(72.7)$ & $.056^{\mathrm{a}}$ \\
\hline Frequency & $22(59.5)$ & $18(42.9)$ & $.141^{\mathrm{a}}$ \\
\hline Nocturnal polyuria & $13(37.1)$ & $14(36.8)$ & $.979^{a}$ \\
\hline First morning urine osmolality (mOsmol/kg) & $871.28 \pm 253.811$ & $767.14 \pm 256.899$ & $.161^{\mathrm{b}}$ \\
\hline Bladder capacity $\%$ & $67.79 \pm 28.080$ & $73.61 \pm 29.999$ & $.385^{b}$ \\
\hline Abnormal urine flow patterns & $11(28.2)$ & $24(53.3)$ & $.020^{\mathrm{a}}$ \\
\hline Post void residual urine(ml) & $10.64 \pm 8.106$ & $17.33 \pm 16.132$ & $.021^{b}$ \\
\hline Dysfunctional voiding & $5(12.8)$ & $15(32.6)$ & $.003^{a}$ \\
\hline Thickened bladder wall & $11(28.2)$ & $4(9.3)$ & $.027^{a}$ \\
\hline
\end{tabular}

Legend: Values are presented as number $(\%)$ or arithmetic mean \pm standard deviation; a-chi-square; b-t-test.

Tab. 3 Descriptive statistics and significance of differences between a group of people with primary $(\mathrm{N}=59)$ and secondary enuresis $(\mathrm{N}=26)$.

\begin{tabular}{|l|l|l|l|}
\hline Characteristics of patients & Primary enuresis (\%) & Secondary enuresis (\%) & P \\
\hline Age (years) & $7.4068 \pm 2.53335$ & $8.0769 \pm 3.21152$ & $.304^{\mathrm{b}}$ \\
\hline The age of sphincter control (months) & $30.4722 \pm 7.76250$ & $30.3182 \pm 5.28598$ & $.935^{\mathrm{b}}$ \\
\hline Urinary tract infection & $14(25.5)$ & $9(34.6)$ & $.393^{\mathrm{b}}$ \\
\hline Constipation & $20(36.4)$ & $9(36.0)$ & $.975^{\mathrm{a}}$ \\
\hline Daytime incontinence & $49(83.1)$ & $22(84.6)$ & $.858^{\mathrm{a}}$ \\
\hline Urgency & $47(83.9)$ & $19(73.1)$ & $.249^{\mathrm{a}}$ \\
\hline Frequency & $28(52.8)$ & $12(46.2)$ & $.577^{\mathrm{a}}$ \\
\hline Nocturnal polyuria & $20(40.8)$ & $7(29.2)$ & $.333^{\mathrm{a}}$ \\
\hline First morning urine osmolality (mOsmol/kg) & $833.7222 \pm 247.82858$ & $811.6429 \pm 291.04602$ & $.789^{\mathrm{b}}$ \\
\hline Bladder capacity \% & $72.4453 \pm 28.81554$ & $67.4625 \pm 29.96836$ & $.490^{\mathrm{b}}$ \\
\hline Abnormal urine flow patterns & $20(34.5)$ & $15(57.7)$ & $.046^{\mathrm{a}}$ \\
\hline Post void residual urine (ml) & $13.6949 \pm 12.42391$ & $15.4800 \pm 15.64747$ & $.580^{\mathrm{b}}$ \\
\hline Dysfunctional voiding & $10(16.9)$ & $10(38.4)$ & $.003^{\mathrm{a}}$ \\
\hline Thickened bladder wall & $10(17.5)$ & $5(20.0)$ & $.791^{\mathrm{a}}$ \\
\hline
\end{tabular}

Legend: Values are presented as number (\%) or arithmetic mean \pm standard deviation; a-chi-square; $b$-t-test. 
strategy in managing children with daytime incontinence include bladder ultrasound, PVR together with uroflowmetry (15). Uroflowmetry is time-consuming as for proper evaluation of bladder emptying, at least two bladder filling cycles need to be done.

Association of enuresis and bladder dysfunction has been reported and small capacity bladder and detrusor overactivity have been the most important (common) urodynamic findings (20-23). In our study there was no difference according to the bladder capacity between the boys and girls and between children with primary and children with secondary NMNE. However, urodynamic studies have indicated that bladder wall thickness was significantly higher in patients with detrusor overactivity and detrusor overactivity was seen in children with primary NMNE as compared to primary MNE (24). According to our study bladder wall thickness was statistically more often in boys. Those findings are probably related to detrusor overactivity in boys. Small capacity bladder and detrusor overactivity cause symptoms of urinary bladder storage function while uroflowmetry examines bladder emptying.

According to the literature it is also crucial to differentiate primary NE from secondary NE or daytime incontinence with a nocturnal component $(25,26)$. In our study an abnormal bladder emptying detected using uroflowmetry was more likely to be associated with secondary NMNE. Maybe this is because in primary NMNE the more common problem is overactive bladder which cause storage bladder problem and in secondary NMNE and in girls the more common are emptying difficulties which are measured by uroflowmetry. Abrams et al. have already proposed that secondary enuresis was more likely to be associated with an organic cause (18).

According to our study dysfunctional voiding was more often in children with secondary NMNE.

Naseri and Hiradfar urodynamic studies had revealed abnormalities in $43 \%$ of MNE and $53 \%$ of NMNE, which shows that abnormal urodynamics is as common in MNE as in NMNE. The majority of their patients had small capacity and low compliance bladders which was indicative of an overactive bladder (27). Some authors found that the only significant difference between the patients with primary NE and those with secondary NE was in the prevalence of constipation which is significantly associated with primary NE (28). In our study the incidence of constipation was less than $30 \%$ of total number of children. Constipation was significantly more often in girls than in boys. Urinary tract infections (UTI) are already recognized as related to staccato flow pattern and dyssinergic voiding $(29,30)$. In our study both dysfunctional voiding and UTI were more often in girls than in boys.

Limitation of this study was in the number of the patients so our conclusions should be confirmed in future larger study. In children with NMNE, children with primary and secondary NMNE should be distinguished.

Despite the fact that some children with primary enuresis also had daily symptoms, uroflow pattern was mostly normal, bell shaped. It is probably because the emptying function of the bladder in those children is normal. In children with primary NMNE we propose primary assessment by bladder ultrasound with PVR, and uroflowmetry to be part of secondary assessment if primary assessment is suspected of obstruction or if therapy failed. Emptying difficulties are more often in girls than boys with NMNE. As for therapy, standard urotherapy, adequate water intake, and regular voiding was implemented in all children. Constipation was treated along with standard urotherapy. Some of children were treated with desmopressin, some with anticholinergic therapy with oxybutinine, and some with dual therapy with both desmopressin and oxybutinin. Animated biofeedback was used for dysfunctional voiding.

\section{CONCLUSIONS}

The UTI, constipation and urinary dysfunctions are statistically significant NMNE symptoms in our study. In our patients with NMNE an abnormal uroflow pattern was in almost half of the cases. It was more often in girls than boys and in children with secondary than in children with primary NMNE.

Based on this finding we propose that in children with secondary NMNE, uroflowmetry always be performed as a first-line examination. In contrast, in children with primary NMNE, it is not necessary to initially perform uroflowmetry, but only as a second-line examination.

\section{CONFLICTS OF INTEREST}

The authors report no conflicts of interest.

\section{REFERENCES}

1. Austin PF, Bauer S, Bower W, et al. The standardization of terminology of lower urinary tract function in children and adolescents: update report from the Standardization Committee of the International Children's Continence Society. Neurourol Urodyn 2016; 35: 471-81.

2. Graham KM, Levy JB. Enuresis. Pediatr Rev 2009; 30: 165-72.

3. Gumus B, Vurgun N, Lekili M, Iscan A, Muezzinoglu T, Buyuksu C. Prevalence of nocturnal enuresis and accompanying factors in children aged 7-11 years in Turkey. Acta Paediatr 1999; 88: $1369 \mathrm{e} 72$.

4. Jarvelin MR, Vikevainen-Tervonen L, Moilanen I, Huttunen NP. Enuresis in seven-year-old children. Acta Paediatr Scand 1988; 77: $148 \mathrm{e} 53$.

5. Forsythe WI, Redmond A. Enuresis and spontaneous cure rate. Study of 1129 enuretis. Arch Dis Child 1974; 49: 259 e63.

6. Hellstrom A, Hanson E, Hansson S, Hjalmas K, Jodal U. Micturition habits and incontinence at age 17ereinvestigation of a cohort studied at age 7. Br J Urol 1995; 76: 231e4.2e5.

7. Butler R, Heron J. The Alspac Study T. Exploring the differences between mono- and polysymptomatic nocturnal enuresis. Scand J Urol Nephrol 2006; 40: 313e9.

8. Abdelfatah D, Shaker H, Ismail M, Ezzat M. Nocturnal polyuria and arginine vasopressin (AVP): A key factor in the pathophysiology of monosymptomatic nocturnal enuresis. Neurorol Urodyn 2009; 28: 506-9.

9. Av Gontard, Neve'us T. Management of disorders of bladder and bowel control in childhood. London: Mac Keith Press; 2006.

10. Franco I, von Gontard A, De Gennaro M; International Children's Continence Society. Evaluation and treatment of nonmonosymptomatic nocturnal enuresis: a standardization document from the International Children's Continence Society. J Pediatr Urol 2013; 9(2): 234-43.

11. Vande Walle J, Rittig S, Bauer S, Eggert P, Marschall-Kehrel D, Tekgul S. American Academy of Pediatrics; European Society for Paediatric Urology; European Society for Paediatric Nephrology; International 
Children's Continence Society. Practical consensus guidelines for the management of enuresis. Eur J Pediatr 2012; 171: 971-83.

12. Fritz G, Rockney R, Bernet W, et al. Practice parameter for the assessment and treatment of children and adolescents with enuresis. J Am Acad Child Adolesc Psychiatry 2004; 43(12): 1540-50

13. Hjalmas K, Arnold T, Bower W, et al. Nocturnal enuresis: an international evidence-based management strategy. J Urol 2004; 171 (6 pt 2): 2545-61.

14. Kalyanakrishnan Ramakrishnan. Evaluation and Treatment of Enuresis. Am Fam Physician 2008; 78(4): 489-96.

15. Chang SJ, van Laecke E, Bauer SB, et al. Treatment of daytime urinary incontinence: a standardization document from the International Children's Continence Society. Neurourol Urodyn 2017; 36(1): 43-50.

16. Hyams JS, Di Lorenzo C, Saps M, Shulman RJ, Staiano A, van Tilburg M. Functional Disorders: Children and Adolescents. Gastroenterology 2016; 150(6): 1456-68.

17. Erasmie U, Lidefelt KJ. Accuracy of ultrasonic assessment of residual urine in children. Pediatr Radiol 1989; 19: 388-90.

18. Abrams P, Cardozo L, Khoury S, Wein A. Incontinence (editors). Paris. Health Publication 2002; 513-51.

19. Wootton J, Norfolk S. Nocturnal enuresis: assessing and treating children and young people. Community Pract 2010; 83:37-9.

20. Yeung CK, Chin HN, Sit FK. Bladder dysfunction in children with refractory nocturnal mono-symptomatic primary nocturnal enuresis. J Urol 1999; 162: 1049-54.
21. Kajiwara M, Inouse K, Kato M, Usui A, Kurihara M, Usui T. Nocturnal enuresis and overactive bladder in children: an epidemiological study. Int J Urol 2006; 13: 36-41.

22. Frank HJS, Pannek BJ. Voiding dysfunction in children: role of urodynamic studies. Urol Int 2002; 69: 297-301.

23. Naseri $M$, Hiradfar $M$. Abnormal urodynamic findings in children with nocturnal enuresis. Indian Pediatr 2012; 49: 401-3.

24. Charalampous S, Printza N, Hashim H, et al. Bladder wall thickness and urodynamic correlation in children with primary nocturnal enuresis. J Pediatr Urol 2013; 9: 334-815.

25. Schaeffer AJ, Diamond DA. Pediatric urinary incontinence: Classification, evaluation, and management. Afr J Urol 2014; 20: 1-13.

26. Lettgen B. Differenial diagnosis for nocturnal enuresis. Scand J Urol Nephrol Suppl 1997; 183: 47-8.

27. Naseri M, Hiradfar M. Monosymptomatic and non-monosymptomatic nocturnal enuresis: a clinical evaluation. Arch Iran med 2012; 15(11): 702-6.

28. Robson WL, Leung AK, Van Howe R. Primary and secondary nocturnal enuresis: similarities in presentation. Pediatr 2005; 115(4): 956-9.

29. Chase J, Austin P, Hoebeke P, mcKenna P. The management of dysfunctional voiding in children: a report from the standardisation comitee of the International Children's continence society. J Urol 2010; 183: 1296-1302.

30. Hoebeke P, Bower W, Combs A, De Jong T, Yang S. Diagnostic evaluation of children with daytime incontinence. J Urol 2010; 183(2): 699-703. 